\title{
Novel and Compact Ultra Wideband Wearable Band- Notch Antenna Design for Body Sensor Networks and Mobile Healthcare System ${ }^{\dagger}$
}

\author{
Mohammad Monirujjaman Khan * and Arifa Sultana \\ 1 Department of Electrical and Computer Engineering, North South University, Bashundhara, Dhaka-1229, \\ Bangladesh; \\ * Correspondence: monirujjaman.khan@northsouth.edu; Tel.: +8801779006296 \\ + Presented at the 1st International Electronic Conference-Futuristic Applications on Electronics, $01-30$ \\ November 2020; Available online:
}

Received: 2 September 2020; Accepted: 21 October 2020; Published: 30 October 2020

\begin{abstract}
Development and study of a novel and very miniaturized ultra-wideband(UWB) wearable band-notch antenna for body sensor networks (BSNs) and mobile healthcare system have been presented in this paper. A very user friendly and reliable software Computer Simulation Technology $(\mathrm{CST})^{\mathrm{TM}}$ Microwave Studio was used for the modeling and simulation purpose of this antenna. The antenna is textile based ultra-wideband notch antenna as it was printed on jeans' textile substrate. The simulated performance parameters such as; return loss, bandwidth, gain, radiation efficiency and radiation patterns of this antenna are demonstrated and analyzed. The main aim of this paper was to design a textile based compact ultra-wideband antenna with the characteristics of band notch in X-band to reject the down link band $(7.25 \mathrm{GHz}-7.75 \mathrm{GHz})$ of satellite communication in the UWB frequency ranges of 3.1 to $10.6 \mathrm{GvHz}$ in order to avoid interference. The simulated results show that this antenna has very well band notch characteristics in the frequency range of 7.25 GHz-7.75 GHz. The overall dimension of the antenna is $25 \mathrm{~mm}$ in length and $16 \mathrm{~mm}$ in width which is very compact. The antenna is printed on $1 \mathrm{~mm}$ Jeans' textile with the dielectric constant of 1.7. This antenna shows very good results, it has compact size and printed on textile material, it has band notch characteristics to avoid interference. Due to all these attractive characteristics it will be good candidate for body sensor networks for mobile healthcare system.
\end{abstract}

Keywords: novel; compact; body sensor networks; mobile healthcare system; band notch; wearable antenna; ultra-wideband; textile; jeans' textile

\section{Introduction}

Now a day's wireless body area networks (WBANs) systems are becoming very popular research topic because of the applications of it in the field of medical, real time health monitoring, entertainments. The low power limit $(-44.3 \mathrm{dBm})$ of UWB systems, high data rate, compact size, large bandwidth attracts a wide range of applications in short range communications, wearable applications in sensor networks, body area networks, wireless positioning system, IoT applications, biomedical imaging, and high data rate small range communications. For small period of UWB pulses, it is simple to persuade high data rate with small latency [1].

According to Federal Communication Communications FCC UWB frequency range is to be from $3.1 \mathrm{GHz}$ to $10.6 \mathrm{GHz}$ [2]. Ultra wideband antenna is the most important elements for establishing UWB communications. Important issue remains in terms of interference with narrowband frequency in the UWB frequency regions 3.1-10.6 GHz. UWB experiences from narrow band interference from WiMAX, WLAN and X band satellite communication channels. It is very crucial to filter out these unwanted narrowband signals in order to develop power efficient UWB communication system for 
wireless body sensors networks. In body area networks antennas will be integrated with the sensors for the health monitoring purpose [1].

Antenna is one of the most important component for any wireless communication system. For the design of efficient UWB system for body sensor networks antenna needs to meet the special requirement in terms of impedance bandwidth, return loss, radiation efficiency, gain and radiation pattern. Recently there is tremendous growing research and interest are realized for the design of UWB wearable antennas [3-16]. UWB antenna design and radio channel modeling for wireless body area networks have been presented in [3-9]. Ultra wideband band north antenna has been pretend in open literature in [12-15]. However, different authors have used various techniques to integrate band notch in UWB antennas [12-15]. Still now there is no breakthrough in the design of UWB suitable band notch antennas. In some articles authors used band rejection for WiMAX and WLAN [9-11, 1415]. Band rejection technique has been used in UWB antennas for X-band downlink satellite communication systems $(7.25-7.75 \mathrm{GHz})[13,14,16]$. However, mostly UWB band notch antenna designs have been focused on FR4 substrate. Some authors presented antennas with bigger in size and they may not be suitable for wearable applications.

This paper developed and analyzed a novel and very compact Jeans' textile based band notch UWB wearable antenna for the health monitoring applications in body sensors networks. The antenna has the band notch characteristics for the rejection of X-band downlink satellite communication systems (7.25-7.75 GHz). Simulation based results of the antenna including with antenna structure have been presented.

\section{Textile UWB Band Notch Antenna Design}

Figure 1a-c demonstrates the details structures of the UWB band notch textile antenna. It shows front and back views of the antenna with detail sizes of each segment and component. This antenna was developed with the help of Computer Simulation Technology (CST) ${ }^{\mathrm{TM}}$ Microwave Studio. The antenna is printed on Jeans' fabric substrate which has a height of $1 \mathrm{~mm}$ and the relative permittivity of the substrate is used as 1.7. The antenna does not have full ground plane in the rear side as noticed from Figure 1c. A slit is introduced to the top of the antenna radiating element to obtain the band notch in the $x$ band frequency range of $(7.25 \mathrm{GHz}-7.85 \mathrm{GHz})$ for satellite communication. The antenna is very compact in size as $25 \mathrm{~mm}$ in length and $16 \mathrm{~mm}$ in width of the full antenna with substrate and ground plane.

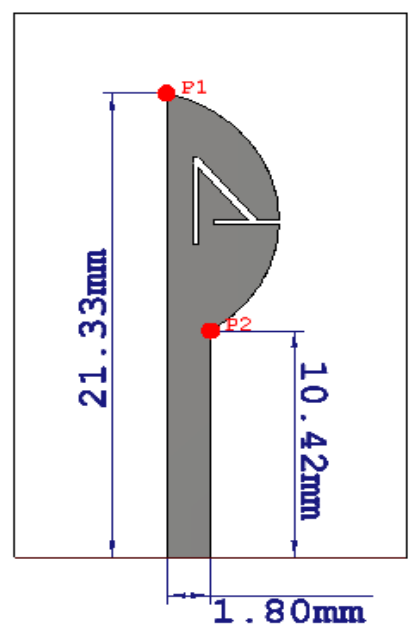

(a)

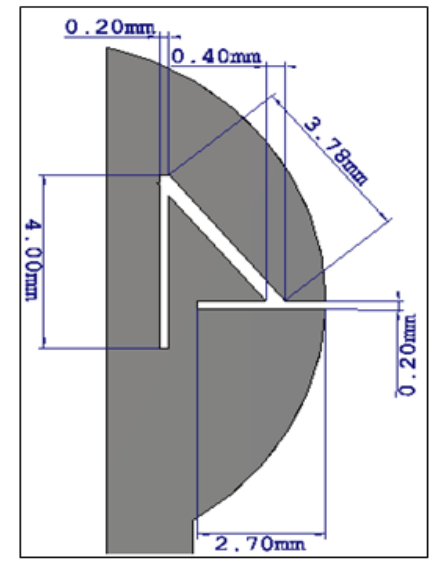

(b)

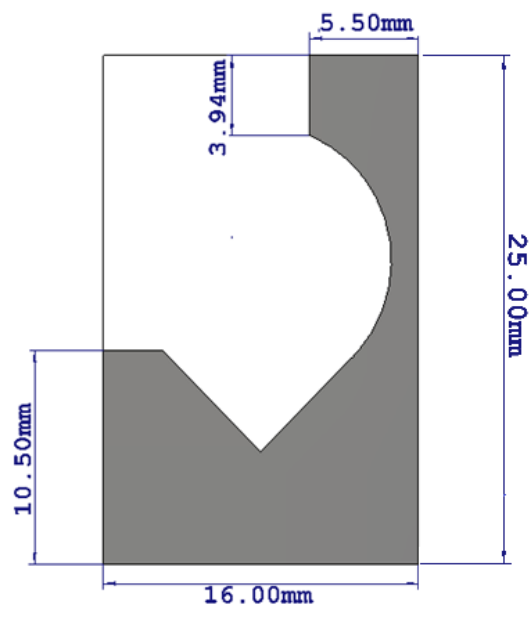

(c)

Figure 1. Ultra wideband band notch textile antenna: (a) front view, (b) Front view with details of slit size, and (c) Back view with showing ground plane size.

\section{Results and Discussions}


In this section the performance parameters such as; return loss impedance bandwidth, gain, radiation efficiency, radiation pattern of the antenna is presented and analyzed. The results were extracted from the simulation done using CST.

\subsection{Return Loss Response}

Figure 2 illustrates the return loss curve of the antenna. The return loss result of this antenna was extracted from the simulation result in CST software. From the Figure 2 it is noted that the antenna works in the range of ultra-wideband frequency band $(3.1 \mathrm{GHz}$ to $10.6 \mathrm{GHz})$ and it shows band notch characteristics in the frequency range of $7 \mathrm{GHz}$ to $7.85 \mathrm{GHz}$ that was one of the goals of this paper. In the frequency range of $7 \mathrm{GHz}$ to $7.85 \mathrm{GHz}$ the return loss values are above $-2 \mathrm{~dB}$ which will allow interference less communication in the UWB system for low power body sensors networks. The presented return loss results meet the estimated aim of this paper. At other frequency bands except band notch regions the return loss values show very good results specially at higher frequency.

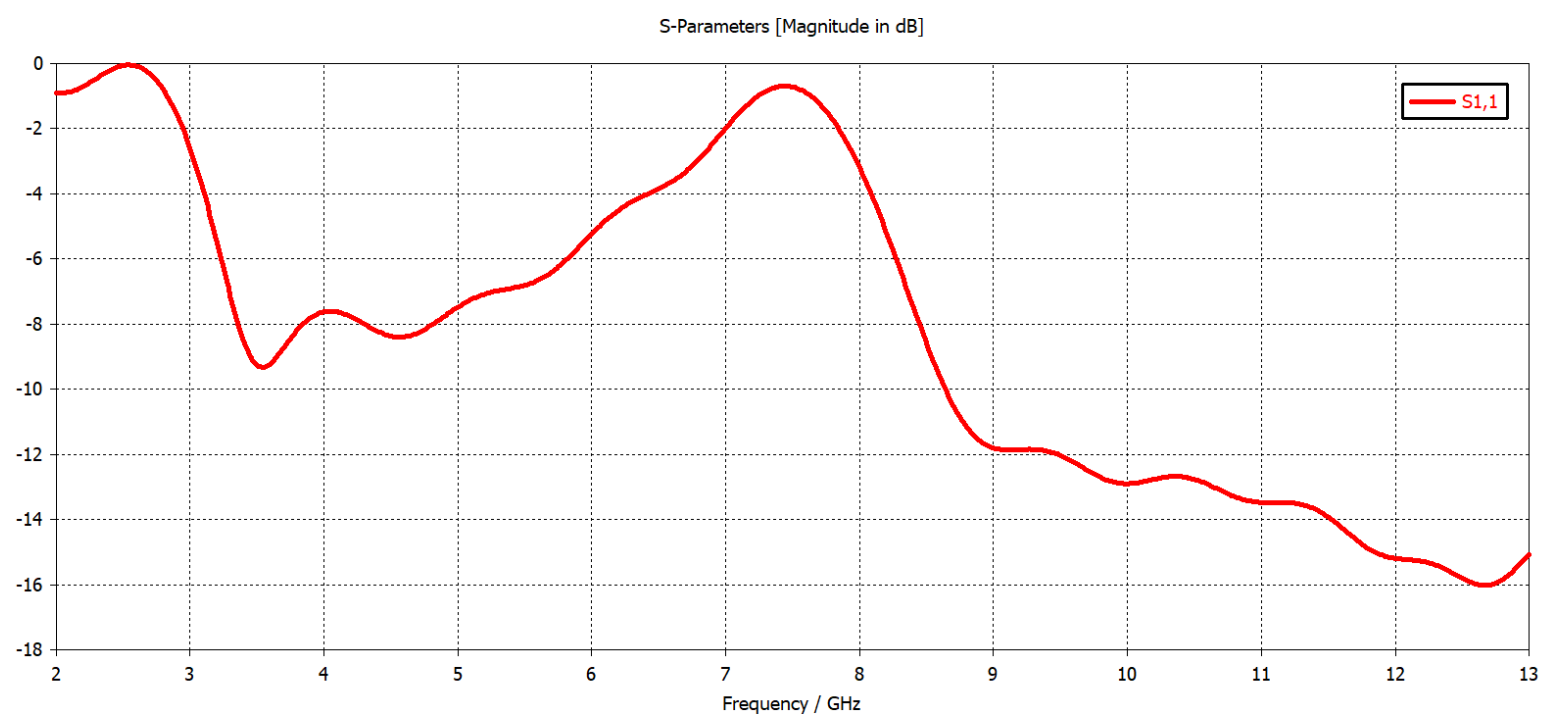

Figure 2. Return loss curve of the ultra-wideband (UWB) notch antenna.

\subsection{Radiation Efficiency and Gain}

In Table 1 simulated radiation apttern and gain of the antenna is listed. The simulated gain and radiation efficiency are extracted from the far field simulated results at the frequencies of $3.5 \mathrm{GHz}$, $5.7 \mathrm{GHz}, 7 \mathrm{GHz}$ and $9 \mathrm{GHz}$. From the Table 1 it is realized that antenna shows higher radiation efficiency at $3.5 \mathrm{GHz}, 5.7 \mathrm{GHz}$ and $9 \mathrm{GHz}$ as comapered to $7 \mathrm{GHz}$ which is expected due the notch at this frequency. As compared to higher frequency band, this antenna shows better efficiency at lower frequencies. Maximum of $84.3 \%$ radiation efficiency is observed at $5.7 \mathrm{GHz}$ for this antenna. The antenna expressed good gain at $3.5 \mathrm{GHz}, 5.7 \mathrm{GHz}$ and $9 \mathrm{GHz}$. The gain is very at $7 \mathrm{GHz}$ which is obvious becasse of noth band here.

Table 1. Gain and radiation efficiency at various frequencies of the antenna

\begin{tabular}{ccccc}
\hline Frequency $(\mathrm{GHz})$ & $3.5 \mathbf{G H z}$ & $5.7 \mathbf{G H z}$ & $7 \mathbf{G H z}$ & $\mathbf{9 ~ G H z}$ \\
\hline Gain $(\mathrm{dBi})$ & 1.643 & 1.76 & -0.20 & 2.86 \\
Radiation Efficiency (\%) & 83.29 & 84.30 & 32.00 & 79.79 \\
\hline
\end{tabular}


In this study, this antenna shows maximum $2.86 \mathrm{dBi}$ gain at $9 \mathrm{GHz}$. From the study it is noticed that higher frequency has higher gain in comparison with the lower frequency band. The lowest gain is noticed at $7 \mathrm{GHz}$.

\subsection{Radioation Patterns}

Figure 3a-h demonstrates the simulated radiation patterns of the antennas at $3.5 \mathrm{GHz}, 5.7 \mathrm{GHz}$, $7 \mathrm{GHz}$ and $10 \mathrm{GHz}$. The radiation patterns have been plotted as plane wise like elevation and azimuth planes.At $3.5 \mathrm{GHz}$, the antenna radiates like omnidirectional in the $\mathrm{XY}$ plane but in the $\mathrm{XZ}$ plane there is a null noticed in the 120 degree angle. At $5.7 \mathrm{GHz}$ in the $\mathrm{XY}$ plane the radiation pattern looks like same as the $3.5 \mathrm{GHz}$ but less null is noticed at the $\mathrm{XZ}$ plane in the 120 degree angle in comparison with $3.5 \mathrm{GHz}$. At higher frquency like $9 \mathrm{GHz}$ the radiation patterns in both planes look like more distoroted compared with lower frequency bands.

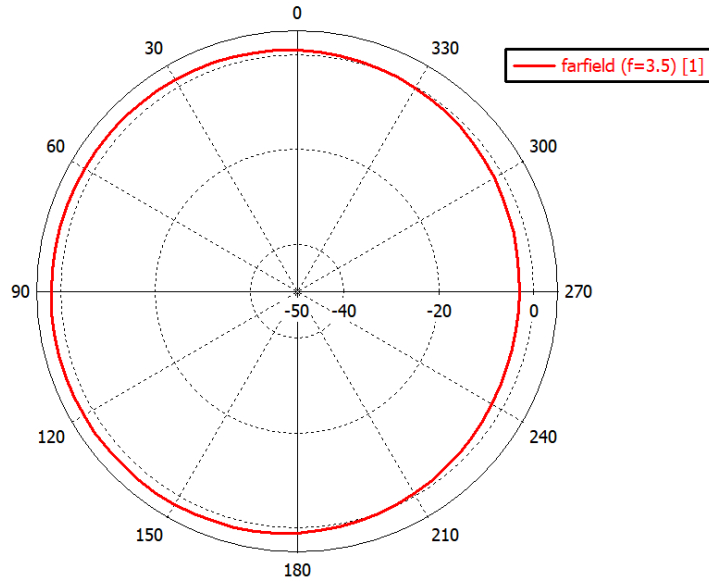

(a)

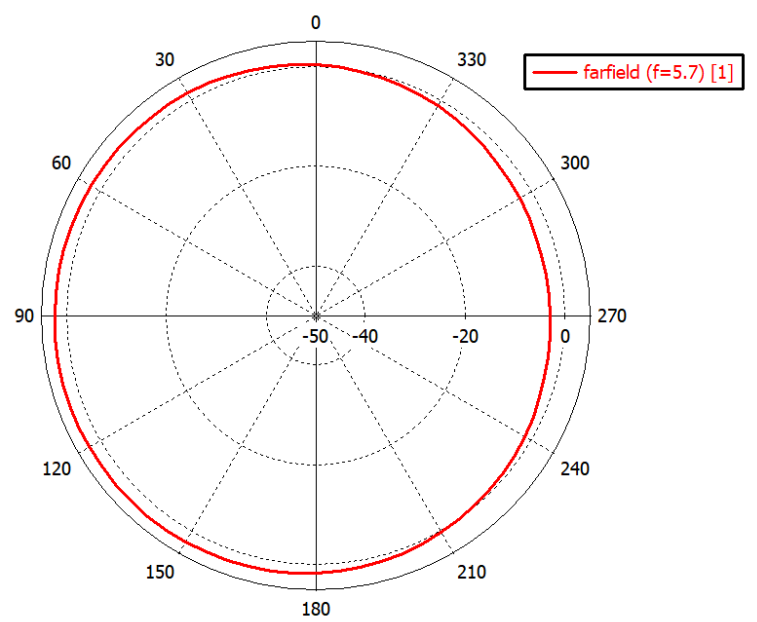

(c)

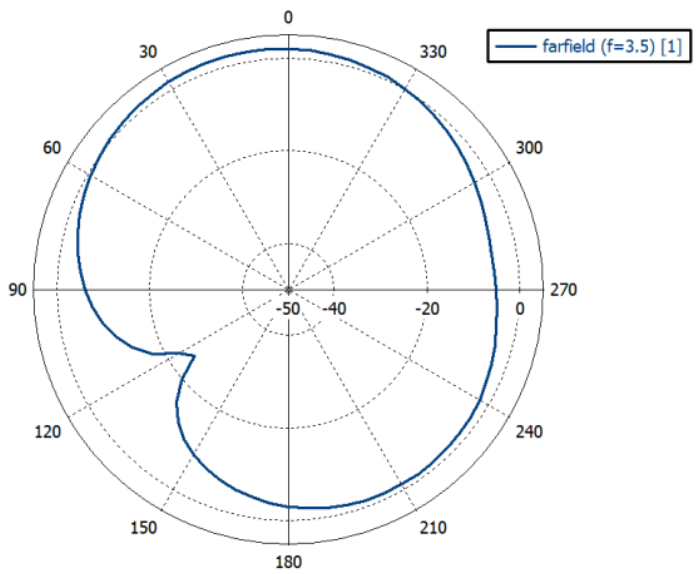

(b)

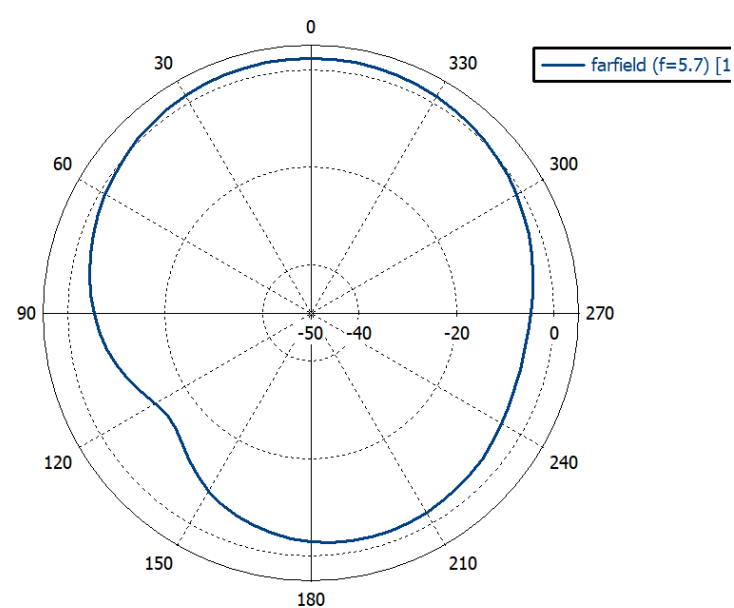

(d) 


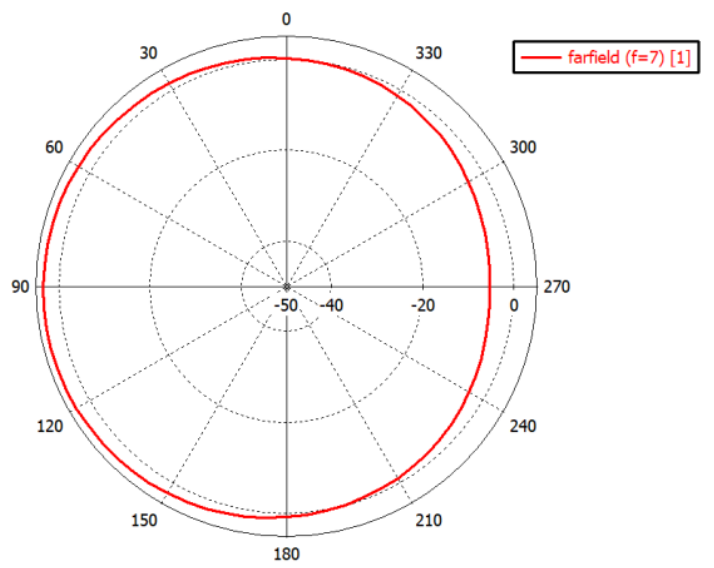

(e)

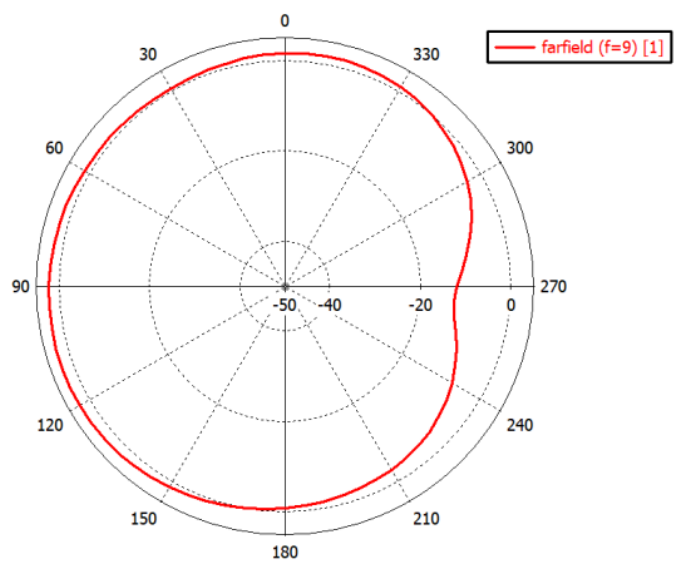

(g)

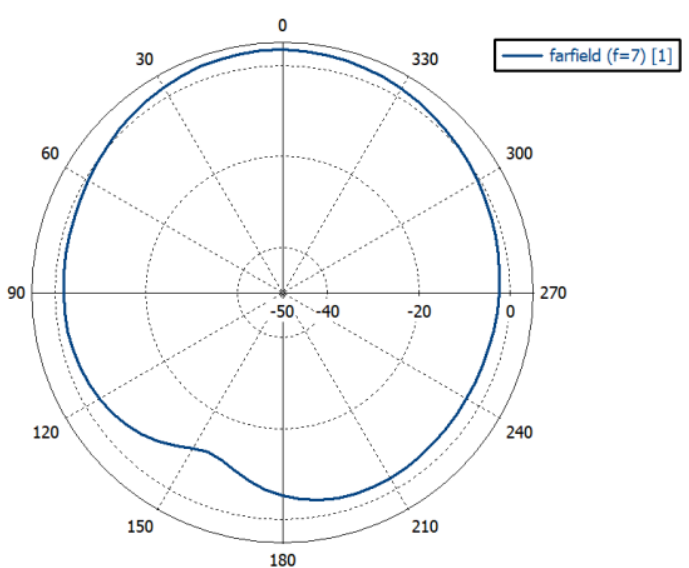

(f)

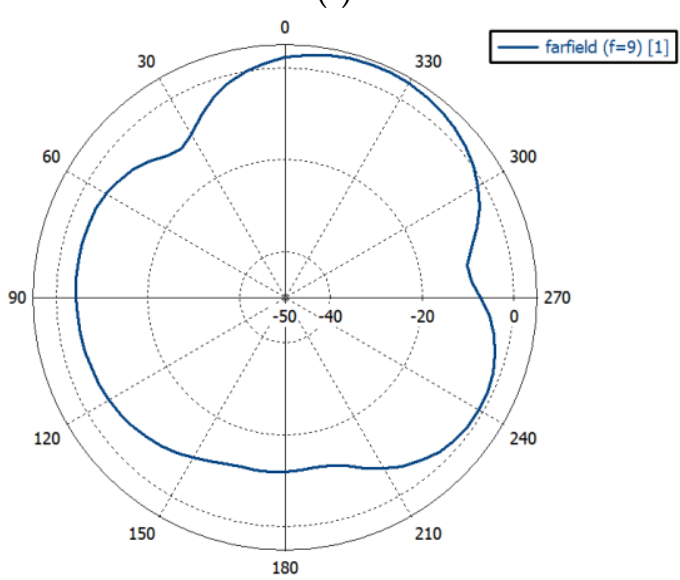

(h)

Figure 3. Radiation patterns of the antennas at different frequencies. (a) $3.5 \mathrm{GHz}, \mathrm{XY}$ Plane; (b) 3.5 GHz, XZ Plane; (c) 5.7 GHz, XY Plane; (d) 5.7 XZ Plane; (e) 7 GHz, XY Plane; (f) 7 GHz, XZ Plane; (g) $9 \mathrm{GHz}$, XY Plane; (h) 9 GHz, XZ Plane.

\subsection{Future Work}

In future, this compact textile antenna will be fabricated on the jeans' substrate and performance parameters will be measured. The simulation results will be compared with the measured results. From the experienced of authors, it is noticed that the simulated results using CST is comparable with the measurements. The antenna has already been simulated on three layers (skin, muscle and fat) human body model to study the human body effects on the antenna performance. Due to page limit it is not possible to provide the on-body simulated results here in this paper. Some simulation based parametric studies also have been carried out. Authors of this paper have plan to summarize all the results and write a research article for MDPI journal soon.

\section{Conclusion}

A novel compact Jeans' textile wearable ultra-wideband band notch antenna for wireless body sensor networks and mobile healthcare system is demonstrated. The antenna works in the ultrawideband frequency ranges of $3.1 \mathrm{GHz}$ to $10.6 \mathrm{GHz}$ with the characteristics of band notch in X-band to reject the down link band $(7.25-7.75 \mathrm{GHz})$ of satellite communication with a view to avoid interference. The antenna is very compact in size and designed on $1 \mathrm{~mm}$ Jeans' textile with the dielectric constant of 1.7. The total height of the antenna is $1.07 \mathrm{~mm}$. The antenna shows very bad results at $7 \mathrm{GHz}$ due to band notch characteristic. However, it shows very good preference parameters at other frequency bands of operation. It is illustrated that maximum $84.3 \%$ radiation efficiency and $2.86 \mathrm{dBi}$ gain are noticed at the frequencies of operations for this antenna. The antenna is textile based which will be good option for wearable applications because it can be printed on the 
Jeans clothing of users. Due to its compact size, novel structure, textile based, band notch characteristics, very good performance parameters, this UWB antenna will be suitable for body sensor networks and mobile healthcare system.

Author Contributions: Both authors have equal contribution of this paper.

Funding: The authors of this paper have not received any external fund for the work and results presented in this paper.

Acknowledgments: Authors would like to thank the ECE Department of North South University.

Conflicts of Interest: The authors declare no conflict of interest.

\section{References}

1. Hall, P.S.; Hao, Y. Antennas and Propagation for Body-Centric Wireless Communications, Artech House, Norwood, Mass, USA, 2006.

2. Federal Communication Commission. First order and report: Revision of part 15 of the Commission's rules regarding UWB transmission systems. Available online: https://www.fcc.gov/document/revision-part-15commissions-rules-regarding-ultra-wideband-1 (accessed on 22 April 2002)

3. Khan, M.; Alam, A.K.M.; Talha, Md, Kumar, Prodip. Investigation of a Compact Ultra Wideband Antenna for Wearable Applications. Int. J. Commun. Antenna Propag. 2014, 4, 124-129.

4. Yeboah-Akowuah, B.; Kosmas, P.; Chen, Y. A Q-Slot Monopole for UWB Body-Centric Wireless Communications, IEEE Trans. Antennas Propag. 2017, 65 (10), 5069-5075

5. Khan, M.M.; Mobin, I.; Palikaras G.; Kallos, E. Study of a small printed quasi-self-complementaryultrawideband antenna for on-body applications. 2012 4th Computer Science and Electronic Engineering Conference (CEEC), 2012, pp. 179-183, doi: 10.1109/CEEC.2012.6375401.

6. Khan, M.M.; Rahman, M.A.; Alomainy, A.; Parini, C. On-Body Radio Channel Performance of a Small Printed Quasi-Self-Complementary Ultra Wideband Antenna. In proceedings of the 2013 2nd International Conference on Advances in Electrical Engineering (ICAEE), Dhaka, 2013, pp. 318-322, doi: 10.1109/ICAEE.2013.6750356.

7. Abbasi, Q.H.; Khan, M.M.; Liaqat, S.; Kamran, M.; Alomainy, A.; Hao, Y. Experimental Investigation of Ultra Wideband Diversity Techniques for On-body Radio Communications, Prog. Electromagn. Res. C. 2013, 34, 165-181.

8. Khan, M.M.; Abbasi, Q.H.; Alomainy, A.; Parini, C. Experimental Investigation of Subject Specific On-Body Radio Propagation Channels for Body-Centric Wireless Communications, Electronics, 2014, 3, $26-42$.

9. Abbasi, A; Hussain, N.; Jeong, M.-J.; Park, J.; Shin, K.S.; Kim, T.; Kim, N. A Rectangular Notch-Band UWB Antenna with Controllable Notched Bandwidth and Centre Frequency, Sensors 2020, 20, 777.

10. Mok, K.Y.; Rhee, Y.C.; Yoon, J.H. Design of a pot-shaped monopole antenna with dual band notched characteristics for UWB application. J. Electromagn. Eng. Sci. 2017, 17, 44-49

11. Liu, H.-W.; Ku, C.-H.; Wang, T.-S.; Yang, C.-F.; Compact Monopole Antenna with Band-Notched Characteristic for UWB Applications. IEEE Antennas Wirel. Propag. Lett. 2010, 9, 201

12. Gheethan, A.A.; Anagnostou, D.E. Dual band-reject UWB antenna with a sharp rejection of narrow and closely-spaced bands. IEEE Trans. Microwave Theory Tech. 2012, 60, 2071-2076

13. Shinde P.N.; Mishra, B.K. On the design of compact UWB antenna with $7.5 \mathrm{GHz}$ band- notch characteristics. In proceedings of the 2013 International Conference on Advances in Technology and Engineering (ICATE), Mumbai, 2013, pp. 1-4, doi: 10.1109/ICAdTE.2013.6524731.

14. Chu, Q.X.; Yang, Y.Y. A Compact Ultrawidwband Antenna with 3.4/5.5 GHz Dual Band-Notched Characteristics. IEEE Trans. Antennas Propag. 2008, 56, 3637-3644

15. Elboushi, A.; Ahmed, O.M.; Sebak, A.R. Study of Ellpitical Slot UWB Antennas with A 5.0-6.0 GHz BandNotch Capability. Prog. Electromagn. Res. C. 2010, 16, 207-222.

16. Doddipalli, S.; Kothari, A. Compact UWB Antenna with Integrated Triple Notch Bands for WBAN Applications. IEEE Access, 2019, 7 183-190. 